\title{
CMEARTICLE
}

\section{Preventing obesity from early childhood}

Xiaoxuan $\underline{G u o}^{1,2}$, MMed, FCFP, Nur Adila Binte $\underline{\text { Ahmad Hatib }}^{3}$, MRCPCH, MMed (Paeds), Chu Shan Elaine $\underline{C h e w}^{4}, \mathrm{MRCPCH}, \mathrm{MMed}$ (Paeds)

Megan, an 18-month-old toddler, was taken to your clinic by her mother for a routine well-child visit. She was a cheerful and sociable child. Her developmental milestones were appropriate for her age and she was otherwise fit for vaccinations. Her height and weight were measured, and she was noted to have a body mass index-for-age of >90th percentile. Apart from appearing chubby, Megan was not dysmorphic, and the rest of the physical examination was normal.

\section{WHAT IS OBESITY?}

Obesity is the excessive accumulation of fat, resulting in adverse health consequences. It is a major risk factor for cardiovascular diseases, which is a leading cause of morbidity and mortality worldwide.

Obesity is the result of a relative excess of energy intake compared to output. Both genes and environmental factors contribute to obesity, with behaviour and environment influencing the development of obesity in genetically-at-risk individuals. It is a growing epidemic worldwide, affecting both developed and developing countries. The World Health Organization (WHO) estimates that in 2016, 39\% of adults worldwide aged 18 years and above were overweight, while $13 \%$ were obese.

Obesity is no longer just an adult disease. Globally, among children and adolescents aged 5-19 years, the prevalence of overweight and obesity has increased from 4\% in 1975 to $18 \%$ in 2016 . Obesity in childhood not only puts children at risk of obesity-related childhood conditions, but also has the long-term effect of predisposing them to adult obesity and noncommunicable diseases related to obesity, such as diabetes mellitus, hypertension and osteoarthritis in adulthood.

The first 1,000 days - the period from conception to two years of age - is an important period of development, which is increasingly being recognised as a stage that affects an individual's risk for developing obesity later on in life. ${ }^{(1)}$ At this stage, taste preferences, dietary habits and lifestyle behaviours start forming, and are easily retained in later life. Interventions at this early stage can help to alter this course before the child's preferences and habits become entrenched.

\section{HOW RELEVANT IS THIS TO MY PRACTICE?}

In Singapore, obesity among children aged 6-18 years rose from $11 \%$ in 2013 to $13 \%$ in $2017 . .^{(2)}$ Results of a survey released in 2017 showed that $70 \%$ of children who were overweight at seven years of age continued to be overweight as adults. ${ }^{(3)}$
Childhood obesity affects both the physical and mental wellbeing of the individual (Box 1). It not only affects the individual but also has immediate as well as long-term implications for the healthcare system when these obesity-related chronic conditions continue and accumulate in adulthood. Hence, early prevention and management of obesity from early childhood is important to avoid these complications.

\section{Box 1. Complications of childhood obesity: \\ - Cardiovascular: Hypertension, hyperlipidaemia \\ - Respiratory: Obstructive sleep apnoea, asthma, obesity hypoventilation syndrome \\ - Gastrointestinal: Gastro-oesophageal reflux, non-alcoholic fatty liver disease, cholelithiasis, non-specific abdominal pain \\ - Renal: Proteinuria, nocturnal enuresis \\ - Endocrine: Type 2 diabetes mellitus, altered onset of puberty, polycystic ovarian syndrome \\ - Neurology: Pseudotumour cerebri \\ - Orthopaedic: Slipped capital femoral epiphysis, Blount disease, pes planus, musculoskeletal pain \\ - Dental: Dental caries \\ - Skin: Acanthosis nigricans, intertrigo, hyperhidrosis, striae - Psychological: Low self-esteem, bullying, eating disorders, mood disorders}

\section{WHAT CAN I DO IN MY PRACTICE?}

Primary care providers, with our experience in preventive care, play a central role in the fight against obesity. Starting from the child's newborn years, frequent encounters for well-child visits and acute conditions present numerous opportunities for the healthcare provider to monitor a child's growth, identify weight issues early and take action as necessary.

Obesity is an intergenerational condition where the need for intervention to address complications intersects with the social determinants of obesity. This can result in an emotionally sensitive situation for families in a healthcare setting. A child's chubbiness may be viewed as acceptable, or desirable and reflective of the caregiver's caregiving abilities. Primary care providers thus need to approach the topic of overweight and obesity in a sensitive,

${ }^{1}$ SingHealth Polyclinics - Punggol, ${ }^{2}$ Family Medicine Academic Clinical Programme, SingHealth Duke-NUS Academic Medical Centre, ${ }^{3}$ General Paediatrics Service, ${ }^{4}$ Adolescent Medicine Service, Department of Paediatrics, KK Women's and Children's Hospital, Singapore

Correspondence: Dr Guo Xiaoxuan, Associate Consultant Family Physician, SingHealth Polyclinics - Punggol, 681 Punggol Drive, Singapore 820681, guo.xiaoxuan@singhealth.com.sg 
non-judgemental and non-stigmatising manner while highlighting the risks of future health consequences.

The family doctor is well placed to address the psychosocial and cultural aspects of feeding, nutrition and weight, and provide family-focused intervention for the child with a high body mass index (BMI), which is preferred over a patientfocused approach. This not only benefits the at-risk child, but also indirectly helps other members of the family to adopt a healthier diet and lifestyle.

\section{Monitor a young child for obesity}

Parental perceptions of the weight status of overweight (and underweight) children have been found to be inaccurate. Hence, objective measures are important for growth assessment, rather than relying on visual or verbal descriptions. ${ }^{(4)}$ Children should have their height (or length), weight and BMI measured and plotted on the corresponding growth charts in their health booklets, which have been derived from population norms. Children aged two years and below should have their height and weight measured every 3-4 months, while those above two years of age should be measured every 6-12 months. ${ }^{(5)}$

For children in Singapore aged 6-18 years, the Health Promotion Board defines BMI > 90th percentile as overweight, while BMI > 97th percentile is considered severely overweight (obesity equivalent). For those aged two years and below, there is currently no consensus on what defines overweight and obesity. However, rapid weight gain in the first two years of life has been recognised as a risk factor for subsequent obesity. ${ }^{(6)}$ Hence, longitudinal plotting of BMI-for-age on the health booklet growth charts serves as a valuable risk assessment tool. The WHO Child Growth Standards for children aged 0-59 months may also be used, where a z-score of $>2.0$ and $>3.0$ is defined as overweight and obese respectively.

\section{Approach to an overweight/obese child in primary care}

When approaching an overweight or obese child in primary care, a careful repeat measurement of the child's height and weight should first be done, using the $\mathrm{WHO}$ recommended guide on measuring a child's growth (see Useful Links), to ensure accurate measurement. Next, a review of the child's medical history should be conducted, together with a physical examination, to identify secondary causes of high BMI that require specialist management (Box 2).

After secondary causes are excluded and/or addressed, the next step would be to look into the child's nutrition and activities. The aim in the management of childhood obesity is commonly not for weight loss, but to control the rate of weight gain through preventive steps and behaviour modification to close the gap between excessive energy intake and insufficient energy expenditure.

\section{Nutrition}

Breastfeeding should be encouraged for as long as possible. The WHO recommends exclusive breastfeeding for the first six
Box 2. Secondary causes of obesity:

- Syndromic obesity: Organic causes of childhood obesity are rare. Specific syndromes that are associated with childhood obesity usually present with accompanying features such as dysmorphism and developmental delays. The most common syndromes that might present in the primary care clinic are Down syndrome and Prader-Willi syndrome.

- Endocrine and hypothalamic disorders: Endocrine disorders may present with weight gain, with height velocity being stunted as compared to primary obesity. These conditions include hypercortisolism, hypothyroidism and growth hormone deficiency. Hypothalamic lesions may cause rapidly progressive, severe obesity. These are usually related to panhypopituitarism, which may be secondary to trauma, tumours, post-surgical or inflammatory disease.

- Medications: Medications such as anti-epileptics and glucocorticoids are associated with weight gain.

months, followed by complementary food with breastfeeding until the child is two years and older.

There are several reasons why breastfeeding is preferred to formula feeding in the prevention of childhood obesity. When compared to breastfed infants, formula-fed infants have a faster growth curve. Formula milk may be higher in energy and protein compared to breast milk. In addition, the composition of breast milk has been found to vary with the nutritional needs and feeding patterns of the child. Latching, as opposed to bottling, has also been suggested to allow better regulation of the infant's own appetite. For these reasons, formula-fed infants could be at a higher risk than their breastfed counterparts of developing obesity later in life. ${ }^{(1)}$

Mothers may choose not to breastfeed or discontinue breastfeeding early for various reasons. ${ }^{(7)}$ While breastfeeding initiation rates are high with about $99 \%$ of new mothers breastfeeding, subsequent continuation of breastfeeding may not be sustainable after hospital discharge. Singaporean mothers with a lower education level were found to be at an increased risk of terminating breastfeeding compared to those with higher education. ${ }^{(8)}$ A mother's perception of breastfeeding was also found to be predictive of continued breastfeeding after six months. ${ }^{(9)}$ Knowledge of these predictive factors can help clinicians to identify challenges faced by different mothers, so that personalised support and education may be offered. Table I presents some common reasons for discontinuing breastfeeding that a mother may encounter at various time points after discharge from hospital.

While complete breastfeeding is ideal, there may be instances where a mother is unable to or chooses not to breastfeed. Ironfortified formula milk is a suitable alternative for most healthy, full-term infants up to one year of age. Formula milk should be prepared according to the manufacturer's instructions (i.e. avoid overconcentration), and infant rice cereals should not be mixed into the milk bottle. Caregivers should be sensitive to the child's hunger cues and feed in response to the infant's needs, rather than adhering to a predetermined schedule and encouraging bottle emptying. As a general guide, infants aged 0-6 months 
Table I. Common reasons for discontinuing breastfeeding and recommended advice.

\begin{tabular}{|c|c|c|}
\hline Age of child & Breastfeeding barriers & Examples of solutions \\
\hline $0-1$ month & $\begin{array}{l}\text { Maternal concerns } \\
\text { over adequacy of milk, } \\
\text { lack of confidence, } \\
\text { pain or discomfort } \\
\text { from breastfeeding, } \\
\text { challenges with } \\
\text { transition, lack of sleep }\end{array}$ & $\begin{array}{l}\text { Lactation consultation, } \\
\text { screening for postnatal } \\
\text { depression, counselling } \\
\text { for emotional support, } \\
\text { family therapy }\end{array}$ \\
\hline 2 months & $\begin{array}{l}\text { Mothers may have } \\
\text { the misconception } \\
\text { that breastfeeding is } \\
\text { only critical in the first } \\
6-8 \text { weeks to boost } \\
\text { their child's immunity }\end{array}$ & $\begin{array}{l}\text { Education for the } \\
\text { mother on the benefits } \\
\text { of breastfeeding } \\
\text { beyond immunity }\end{array}$ \\
\hline \multirow[t]{2}{*}{$3-6$ months } & $\begin{array}{l}\text { Mothers returning to } \\
\text { work }\end{array}$ & $\begin{array}{l}\text { Education and } \\
\text { planning for expressed } \\
\text { breast milk feeding }\end{array}$ \\
\hline & Introduction of solids & $\begin{array}{l}\text { Complement solids } \\
\text { with breast milk, rather } \\
\text { than formula milk }\end{array}$ \\
\hline$\geq 7$ months & $\begin{array}{l}\text { Child may self-wean. } \\
\text { Maternal psychosocial } \\
\text { factors }\end{array}$ & $\begin{array}{l}\text { Education and } \\
\text { reassurance tailored to } \\
\text { the specific maternal } \\
\text { psychosocial factor, } \\
\text { e.g. dealing with pressure } \\
\text { of public perception on } \\
\text { breastfeeding beyond } \\
\text { a certain age }\end{array}$ \\
\hline
\end{tabular}

should take approximately $150-200 \mathrm{~mL} / \mathrm{kg} /$ day of formula milk. The frequency of feeds varies for each child and at different ages, from every 2-3 hours for newborns, to every 3-4 hours at three months of age, and every $4-5$ hours by six months of age. At 6-12 months, when the child's growth velocity slows and solids are introduced, infants should take about $120 \mathrm{~mL} / \mathrm{kg} /$ day of formula milk. ${ }^{(10)}$ Overnight feeds should be discouraged if the child is able to sleep through the night.

Caregivers who are anxious about the adequacy of feeds should have their concerns acknowledged and addressed to ensure that the child receives appropriate nutrition without overfeeding. Routine monitoring of growth during well-child visits can help to guide the family doctors in identifying any feeding concerns in the first few years of life.

Once a child starts taking more solids from 12 months onwards, there are several common nutritional areas that can be explored to reduce excessive energy intake. These are presented in Table II.

\section{Activities}

Reducing sedentary activities has the effects of reducing caloric intake, as well as shifting the focus to other activities that expend more energy.

In developed countries, much of the sedentary activity comes in the form of screen time on television and handheld devices. In
Table II. Recommendations to prevent obesity when a child takes more solids from 12 months onwards.

\begin{tabular}{|c|c|}
\hline Feeding & Recommendation(s) \\
\hline $\begin{array}{l}\text { Supplemental } \\
\text { formula milk }\end{array}$ & $\begin{array}{l}\text { An infant should take no more than an average } \\
\text { of } 750 \mathrm{~mL} \text { of formula milk per day, as it can } \\
\text { interfere with solid food intake. Cow's milk (or } \\
\text { full cream milk) should be encouraged in place } \\
\text { of formula. }\end{array}$ \\
\hline $\begin{array}{l}\text { Portion size and } \\
\text { frequency of } \\
\text { feeding }\end{array}$ & $\begin{array}{l}\text { Responsive feeding, self-feeding and } \\
\text { self-regulation should be encouraged. Avoid } \\
\text { an authoritarian feeding style, e.g. forcing the } \\
\text { child to finish all the food on the plate. }\end{array}$ \\
\hline $\begin{array}{l}\text { Sugar-sweetened } \\
\text { beverages }\end{array}$ & $\begin{array}{l}\text { Sugar-sweetened beverages should be } \\
\text { avoided, in keeping with the World Health } \\
\text { Organization's recommendation for no added } \\
\text { sugar (and salt) in the first two years of life. In } \\
\text { addition to increasing body mass index, rates } \\
\text { of dental caries are also higher among children } \\
\text { who consume sugar-sweetened beverages. } \\
\text { This is not limited to sodas and artificially } \\
\text { sweetened beverages but applies to fruit juices, } \\
\text { malted drinks, herbal tea and probiotic drinks } \\
\text { as well. }\end{array}$ \\
\hline $\begin{array}{l}\text { Fruits and } \\
\text { vegetables }\end{array}$ & $\begin{array}{l}\text { For infants aged } 6-12 \text { months, the daily } \\
\text { recommendation is half a serving of fruit and } \\
\text { half a serving of vegetables. For toddlers aged } \\
1-2 \text { years, the daily recommendation is half } \\
\text { to one serving of fruit and half a serving of } \\
\text { vegetables. }\end{array}$ \\
\hline Family meals & $\begin{array}{l}\text { Family meals from } 12 \text { months of age should } \\
\text { be encouraged, when food texture should } \\
\text { be similar to adult food, but with minimal } \\
\text { or no added salt or sugar. Family meals are } \\
\text { associated with higher quality meals with less } \\
\text { oil and salt and more fruits and vegetables } \\
\text { compared to eating out. }\end{array}$ \\
\hline
\end{tabular}

addition, it has also been found that children who spend more time watching television tend to consume more of the advertised items, such as sweets, sugary beverages and salty snacks. ${ }^{(11)}$ Apart from its effects on obesity, excessive screen time can also affect a child's cognitive, language and social/emotional development. The family physician should start the conversation about screen time early, beginning with an understanding of the family's media use habits. Box 3 lists the steps that can be taken to help set healthy habits from a young age. ${ }^{(12)}$

Caregivers should avoid having the infant spend too much time in confining equipment such as car seats, swings, strollers and exersaucers. Time should be set aside each day for active, unstructured play. This not only helps with motor skill development, but also contributes to energy expenditure. Children with higher levels of physical activity in early childhood have been found to have better cardiovascular fitness indicators. ${ }^{(13)}$ In addition to developing the musculoskeletal system in areas such as posture, coordination and strength, physical activity also helps with cognitive and social development, mental health and self-esteem. 
Box 3. Steps that may be taken to help set healthy screen time habits from the start:

- Media exposure based on age

- For children younger than 18-24 months, avoid digital media use (other than video chatting).

- For children aged 2-5 years, limit screen time to 1 hour per day.

- Keep bedrooms, mealtimes and playtimes screen-free.

- Turn off televisions and digital devices when not in use.

- No screens 1 hour before bedtime.

- Curate the quality of the digital content, choosing high-quality and interactive content with educational value. View media content together with the child and reteach the content to help them understand and apply it to the world around them.

- Avoid using screens as the only means to calm a child.

\section{Family-based approach}

A child's relationship with food starts at home and is moulded by the behaviours and attitudes of caregivers and family members towards their food and mealtimes. For example, it is not uncommon for caregivers to use food as a reward or a means of control over the child. The eating preferences of household members and the types of food in the house also influence the food options that a child is exposed to. Similarly, attitudes towards activities, whether physical or sedentary, begin from the home and immediate community. These environmental factors direct the child's perception and eventual relationship with food and physical activity, which in turn contribute to the risk or successful management of obesity later in life.

Prevention and management of childhood obesity should, therefore, be family-focused rather than patient-focused. Parental role-modelling plays an important role in promoting physical activity and preventing obesity. ${ }^{(14,15)}$ Strategies should target the caregivers and involve household-wide changes for a higher rate of success and long-term effectiveness. Healthy nutritional and physical activity habits in the home environment help to support and reinforce the desired behaviours in a child and reduce barriers to change. Person-centric forms of counselling, such as motivational interviewing, may be adopted to guide families to make these positive changes.

\section{WHEN SHOULD I REFER TO A SPECIALIST?}

Primary care providers play an important role in early identification of overweight children and to provide brief intervention. However, there are instances in which primary care providers should provide follow-up for children with high $\mathrm{BMI}$ and refer them to a tertiary centre for further investigation or specialist management. These include: rapid weight gain; increase in weight with slowing height growth; suspected secondary cause for obesity; severe obesity, especially if associated with comorbidities; or failure of primary care management after a six-month trial.

Referral to a dietician with paediatric experience may also be helpful for a more comprehensive nutritional assessment, meal planning and counselling.

\section{USEFUL LINKS}

- Growth Charts: https://www.healthhub.sg/sites/assets/Assets/ Programs/screening/201810/pdf/health-booklet-2014.pdf (accessed March 29, 2021)

- Child Growth Standards, WHO: https://www.who.int/ childgrowth/en/ (accessed March 29, 2021)

- Measuring a Child's Growth, WHO: https://www.who. int/childgrowth/training/module_b_measuring_growth.pdf (accessed March 29, 2021)

\section{TAKE HOME MESSAGES}

1. BMI-for-age should be tracked and plotted over time for early identification of young children at risk of being overweight or obese.

2. Young children with uptrending or persistently high BMIfor-age (i.e. > 90th percentile) should receive management by the primary care provider to avoid excessive weight gain. This begins with early identification of at-risk children and education of caregivers on the potential implications of childhood obesity for the future health of the child.

3. Primary care providers should provide preliminary assessment and management to address modifiable risk factors in childhood, such as adopting healthy nutrition and physical activity habits, to prevent childhood obesity.

4. Management strategies to prevent obesity during childhood should be family-based, rather than focused on the child, and centred around long-term healthy behavioural and lifestyle changes.

Following an evaluation of Megan's diet and activity level, you identified that she was taking more than $750 \mathrm{~mL}$ of formula milk a day on top of regular meals and snacks. She was also taking a packet of sugar-sweetened beverage with each meal. Her mother was educated on age-appropriate weaning strategies and the importance of preventing childhood obesity. You also discussed strategies to slowly decrease Megan's formula milk and sugarsweetened beverage consumption. Cow's milk was also suggested to replace formula milk. When Megan was reviewed six months later, her body mass index-for-age was in the 75-90 percentile. She was well, cheerful and developmentally appropriate for her age. You provided anticipatory behaviour and lifestyle advice, and scheduled her next well-child review in 6-12 months.

\section{ACKNOWLEDGEMENTS}

The authors wish to acknowledge Ethel Lim Jie Kai (Dietician, Department of Nutrition and Dietetics, KK Women and Children's Hospital, Singapore) for her input, and Dr How Choon How for his invaluable thoughts and feedback in the writing of this paper. 


\section{REFERENCES}

1. Mameli C, Mazzantini S, Zuccotti GV. Nutrition in the first 1000 days: the origin of childhood obesity. Int J Environ Res Public Health 2016; 13:838.

2. Chia SL. Obesity trend and programmes. In: Ministry of Health News Highlights. Available at: https://www.moh.gov.sg/news-highlights/details/obesity-trend-andprogrammes. Accessed November 1, 2020.

3. Lai L. Chubby kids are more likely to be fat as adults. The Straits Times 2017 Jun 20. Available at: https://www.straitstimes.com/singapore/health/chubbykids-are-more-likely-to-be-fat-as-adults. Accessed November 1, 2020.

4. Cheng TS, Loy SL, Cheung YB, et al. Singaporean mothers' perception of their three-year-old child's weight status: a cross-sectional study. PLoS One 2016; 11:e0147563.

5. Yap F, Lee YS, Aw MMH. Growth assessment and monitoring during childhood Ann Acad Med Singap 2018; 47:149-55.

6. Zheng M, Lamb KE, Grimes C, et al. Rapid weight gain during infancy and subsequent adiposity: a systematic review and meta-analysis of evidence. Obes Rev 2018; 19:321-32.

7. Li R, Fein SB, Chen J, Grummer-Strawn LM. Why mothers stop breastfeeding: mothers' self-reported reasons for stopping during the first year. Pediatrics 2008 122 Suppl 2:S69-76.
8. Pang WW, Aris IM, Fok D, et al; GUSTO Study Group. Determinants of breastfeeding practices and success in a multi-ethnic Asian population. Birth 2016; 43:68-77.

9. Foo LL, Quek SJ, Ng SA, Lim MT, Deurenberg-Yap M. Breastfeeding prevalence and practices among Singaporean Chinese, Malay and Indian mothers. Health Promot Int 2005; 20:229-37.

10. Shaw V, Lawson M. Clinical Paediatric Dietetics. 3rd ed. Blackwell Publishing; 2007

11. Sahoo K, Sahoo B, Choudhury AK, et al. Childhood obesity: causes and consequences. J Family Med Prim Care 2015; 4:187-92.

12. Council On Communications And Media. Media and young minds. Pediatrics 2016; 138:e20162591.

13. Proudfoot NA, King-Dowling S, Cairney J, et al. Physical activity and trajectories of cardiovascular health indicators during early childhood. Pediatrics 2019; 144:e20182242.

14. Crumbley CA, Ledoux TA, Johnston CA. Physical activity during early childhood: the importance of parental modeling. Am J Lifestyle Med 2019; 14:32-5.

15. Natale RA, Messiah SE, Asfour L, et al. Role modeling as an early childhood obesity prevention strategy: effect of parents and teachers on preschool children's healthy lifestyle habits. J Dev Behav Pediatr 2014; 35:378-87. 


\section{SINGAPORE MEDICAL COUNCIL CATEGORY 3B CME PROGRAMME} (Code SMJ 202104A)

1. It is acceptable for a child to be overweight as they will outgrow their weight when they are older.

2. Obesity can impact children both physically and psychologically.

3. Obesity is solely due to genetics and is therefore not modifiable.

4. Type 2 diabetes mellitus only affects overweight individuals if they are adults.

5. All children who are at risk for obesity should be referred for specialist management.

6. The caregiver's description is a reliable way to assess a child's weight and height in place of clinical measurements.

7. Children above the age of two years should have their weight, height and body mass index (BMI) measured every 6-12 months.

8. A child with a BMI-for-age above the 90th percentile is considered overweight based on local reference growth charts.

9. Most cases of obesity in early childhood are due to endogenous causes.

10. One aim of management of obesity in early childhood is to reduce excessive energy intake and increase energy expenditure so as to achieve controlled weight loss.

11. Active unstructured play has multiple benefits for a child, such as motor skills development and increased energy expenditure.

12. Screen time should be limited to one hour per day of high-quality monitored content with educational value for children aged 18 months and above.

13. It is recommended that children above the age of 12 months switch to low-fat whole cow's milk to prevent the risk of early childhood obesity.

14. The benefits of breastfeeding are especially crucial in the first 6-8 weeks to boost the child's immunity.

15. After the first six months, the World Health Organization recommends complementary food with breastfeeding until the child is aged two years and older.

16. Natural fruit juices that are not artificially sweetened can be offered to children above 12 months as alternatives to fresh whole fruits.

17. Eating meals as a family is one of the recommendations for the prevention of early childhood obesity.

18. The first 1,000 days - the period from conception to two years of age - is a period when interventions can potentially affect an individual's risk for developing obesity in adulthood.

19. Aside from orthopaedic complications such as slipped capital femoral epiphysis, pes planus and Blount disease, early childhood obesity commonly predisposes one to stunted growth and short stature.

20. The primary physician should use a family-centred approach to manage early childhood obesity, rather than a patient-focused approach.

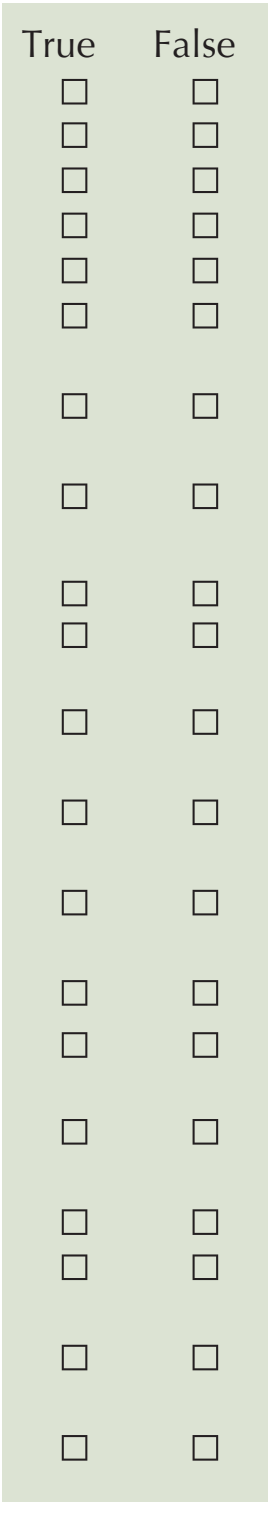

\section{Doctor's particulars:}

Name in full:

MCR no.:

Specialty:

Email:

\section{SUBMISSION INSTRUCTIONS:}

Visit the SMJ website: http://www.smj.org.sg/current-issue and select the appropriate quiz. You will be redirected to the SMA login page.

For SMA member: (1) Log in with your username and password (if you do not know your password, please click on 'Forgot your password?'). (2) Select your answers for each quiz and click 'Submit'.

For non-SMA member: (1) Create an SMJ CME account, or log in with your SMJ CME username and password (for returning users). (2) Make payment of SGD 21.40 (inclusive of $7 \%$ GST) via PayPal to access this month's quizzes. (3) Select your answers for each quiz and click 'Submit'.

RESULTS:

(1) Answers will be published online in the SMJ June 2021 issue. (2) The MCR numbers of successful candidates will be posted online at the SMJ website by 10 June 2021. (3) Passing mark is $60 \%$. No mark will be deducted for incorrect answers. (4) The SMJ editorial office will submit the list of successful candidates to the Singapore Medical Council. (5) One CME point is awarded for successful candidates. (6) SMC credits CME points according to the month of publication of the CME article (i.e. points awarded for a quiz published in the April 2021 issue will be credited for the month of April 2021, even if the deadline is in June 2021).

Deadline for submission (April 2021 SMJ 3B CME programme): 12 noon, 3 June 2021. 